\title{
Implementing volunteer peer mentoring as a supplement to professional efforts in primary rehabilitation of persons with spinal cord injury
}

\author{
Dorthe D. Hoffmann ${ }^{1} \cdot$ Joan Sundby ${ }^{1} \cdot$ Fin Biering-Sørensen ${ }^{2,3} \cdot$ Helge Kasch $\mathbb{C}^{1,4}$
}

Received: 9 November 2018 / Revised: 30 April 2019 / Accepted: 9 May 2019 / Published online: 23 May 2019

(c) The Author(s) 2019. This article is published with open access

\begin{abstract}
Study design A feasibility study, supplemented by a noncontrolled pretest/posttest.

Objectives To examine if a nationwide volunteer peer-mentoring program for in-patients with acute/subacute spinal cord injury is feasible and achievable.

Setting The Spinal Cord Injury Center of Western Denmark and Clinic for Spinal Cord Injuries, Rigshospitalet, Denmark. Methods Volunteer mentor groups were formed similarly in two highly specialized SCI centers covering Denmark. Hospital staff was responsible for referral to the mentoring project and for the interdisciplinary evaluation of patient eligibility. At each of the two centers, a person living with the consequences of SCI coordinated the intervention in collaboration with healthcare personnel. Designated project personnel introduced eligible participants to the project. Staff at the SCI centers arranged to fit in the supplementary mentoring with ongoing treatment. A self-report questionnaire was completed prior to and after peer intervention. Outcome: patient reports regarding mentoring sessions, change in quality of life (QoL), depression items from the Short Form Health Survey (SF-36), pain frequency and intensity (11-point Numerical Rating Scale).

Results A nationwide mentor corps was established. Fifty-two eligible in-patients completed the study. Significant improvement in QoL was found after mentoring. Frequency and intensity of pain did not change, although five out of nine depression items improved significantly. A majority (94\%) of the participants recommended others to meet with a peer mentor.

Conclusions Establishing a nationwide volunteer mentor system at a highly specialized neuro-rehabilitation units for SCI in-patients is both feasible and acceptable.
\end{abstract}

\section{Introduction}

Spinal cord injury (SCI) is a relatively rare but life-altering condition, regardless of the extent and severity of the injury

Supplementary information The online version of this article (https:// doi.org/10.1038/s41393-019-0294-0) contains supplementary material, which is available to authorized users.

\footnotetext{
Helge Kasch

Helge_Kasch@clin.au.dk

Spinal Cord Injury Center of Western Denmark, Viborg, Denmark

2 Clinic for Spinal Cord Injuries, Rigshospitalet, Denmark

3 University of Copenhagen, Copenhagen, Denmark

4 Department. of Clinical Medicine, Aarhus University, Aarhus, Denmark
}

[1]. The world-wide incidence of SCI is estimated to be between 250,000 and 500,000 per year. Of the persons affected, 20-30\% show clinically significant symptoms of depression, which is substantially higher than the general population $[1,2]$. Persons with SCI score their quality of life $(\mathrm{QoL})$ lower than the general population [3, 4]. Furthermore, the majority of persons with SCI suffer from pain [5], and they experience diminished participation in employment, recreation, and quality of interpersonal relationships in general $[6,7]$.

Several efforts are made to counter these issues through rehabilitation, described by $\mathrm{WHO}$ as a highly person oriented health strategy, consisting of "a set of interventions designed to optimize functioning and reduce disability in individuals with health conditions in interaction with their environment" [8]. The set of interventions in rehabilitation consists of many different options and combinations thereof 
largely depending on in which part of the world the rehabilitation takes place. One option is to include peers and their support and counseling in the variety of interventions in rehabilitation.

The concept "peer support" could be defined as providing assistance and encouragement by an individual considered equal [9], and "peer counseling" as a "combination of philosophical and methodological application of skills in basic human communication such as active listening, problem solving, resource identification and the support of a fellow human being" [10].

Healthcare services around the world include peer support as a significant element [9]. For example, in diabetes $[11,12]$ and cancer [13] rehabilitation, peer supported and even peer lead interventions are widely used in various forms, and they are often reported to have a positive and promising outcome; however, the scientific quality of evidence is low when it comes to determining which models and elements of peer support are best suited and most effective. In mental health services peer mentoring seems to have a positive influence on wellbeing in patients with mental disorders $[14,15]$ and in persons who have suffered a traumatic brain injury [16]. Recognizing the positive effects, specialist SCI rehabilitation centers also frequently provide peer support as an integral part of the service $[10,17]$. In a randomized controlled trial [18] Gassaway et al. found that intensive one-to-one peer mentoring during and after SCI rehabilitation lead to greater gains in selfefficacy and to fewer days of rehospitalisation in the first 180 days after discharge.

Peer support and counseling come in many different forms and combinations: One-to-one or group-based, faceto-face or internet/telephone-based meetings, and peers as unpaid volunteers or as employed peer-workers. However, there is a lack of scientific evidence regarding the effectiveness of different forms of peer support in rehabilitation of persons with SCI [7].

Studies have shown that professionals can provide medical advice and information, whereas peers can be role models, and a supportive peer can be a powerful motivator and show by example that life after SCI can be meaningful [10]. Peers provide hope and make the newly injured person able to visualize his/her own potential for social participation [19]. Peer mentoring can be empowering and help newly injured towards coming to terms with their injury [17].

Peers are described as having credibility because "they have lived it all"; a living example or role model of what the SCI patients could achieve and a resource for how to achieve it [20]. People learn more and they try harder when they learn from others that they perceive to be like themselves, managing similar circumstances [18].

A common complaint of persons with neurological impairments is that their therapists know very little about living with disability, and thereby therapists are only providing little real-life experiential knowledge to the patients [21]. Furthermore, studies have shown that people with SCI need support from healthcare professionals, family, friends, and from other persons with SCI [22].

Denmark is a small country with 5.8 million inhabitants. Incidence of SCI is 130 per year [23, 24]. All primary rehabilitation after SCI in Denmark is concentrated at only two multidisciplinary and highly specialized rehabilitation centers, solely receiving patients diagnosed with spinal cord lesions. The two centers provide both in-patient hospitalization and out-patient clinics with life-long follow-up. From the acute or subacute phase at hospitals, patients are admitted to one of the two rehabilitation centers, depending on origin.

After discharge from primary rehabilitation, regular lifelong out-patient clinic visits are offered. Readmission for inpatient stays at one of the centers is sometimes necessary. In Denmark healthcare is provided (including rehabilitation) free of charge for the individual.

A recent Danish study found that the major challenges of returning to one's own home after initial rehabilitation could be summarized into one term: "interpersonal relations". For the individual person, leaving the rehabilitation center and peers it is difficult as you leave behind the persons that really understand what it means to live with an SCI [25]. Further research is needed to identify interventions that could enhance QoL during the early recovery and transition from SCI rehabilitation to home [26].

The purpose of this study was to investigate if organizing a nationwide cross-organizational peer mentoring system for in-patients with SCI in a primary rehabilitation as a supplement to high level professional neuro-rehabilitation would be feasible in a nationwide hospital setting and if it would be acceptable for patients to becoming mentees.

\section{Methods}

The study was approved by the Danish Regional Ethics Committee, (journal number 2007-58-0010). The approval did not include access to electronic medical records.

Data were collected during a one-year inclusion period (1 January 2016 to 31 December 2016) in a joint venture between the SCI centers of Eastern and Western Denmark and RYK, the Danish Spinal Cord Injuries Association user organization.

\section{Study design and outcome measures}

The design of this study was planned by a group of interdisciplinary professionals from the two rehabilitation centers and board members of the Danish Spinal Cord Injuries 
Association (RYK). The study was conducted as a feasibility study. Questionnaires were provided to mentees prior to the first and immediately after the last peer intervention. Our goal was to include 50 participants (i.e. mentees) in the project. The number of participants and the number of sessions were decided based on support obtained by funding made available for the study.

The following data were obtained through self-report questionnaires: Demographic data (age, gender, SCI level, cause of injury, social status, time since injury), QoL (International SCI QoL Basic Data Set [27] and selected parts of Short Form SF-36 v1 [28] (items 9a-9i) in a validated Danish version), pain score numeric rating scale (11-NRS) [29], and reported individual experiences with peer mentoring. We asked about the number of meetings and the satisfaction with the number of meetings. Furthermore, we asked whether mentees were satisfied with the mentor match that had been made for them.

The purpose of collecting data regarding QoL and pain was to monitor the participants' health conditions during the intervention period.

SF-36 was chosen as a widely used as self-reported health-related outcome measure. SF-36 has shown to be applicable in SCI populations [30] and is recommended by The Spinal Cord Injury Rehabilitation Evidence Project as an objective measure of QoL in SCI [31]. Version 1 has been translated into many languages, including Danish. The SF-36 originally contains eight dimensions of health, but in this study only the part describing general health during the past 4 weeks was applied (items 9a-i). All questions posed to mentees in the study have been provided as supplementary material available for readers.

All nonparticipants (i.e. all patients that were in-patients but did not participate in mentoring sessions) were asked to answer a few questions about age, gender and if they had met, talked to, or participated in activities with one of the employed mentor coordinators. Finally, we asked which topics mentees discussed with the mentor coordinators. The nonparticipants answered the questionnaires within the last 2 days before discharge.

\section{Eligibility criteria}

\section{Mentees}

Inclusion criteria: Persons with SCI, aged 18 years or more, who were primarily admitted to an in-patient hospital stay at a Danish SCI rehabilitation center and being able to understand written and verbal Danish at a sufficient level, were eligible to participate in the project.

Exclusion criteria: In order to ensure that mentors were not exposed to tasks and situations that would be very difficult to handle as nonprofessionals, patients with severe dementia, or other severe cognitive or psychiatric disorders (based on a conference between staff and project personnel) were excluded.

The interdisciplinary teams at the SCI centers were responsible for evaluating all newly admitted patients and their potential of participation in the project, evaluating fulfillment of in- and exclusion criteria and deciding when it would be feasible for the patient to receiving peer mentoring. Evaluations were based on subjective assessments made by the interdisciplinary teams in collaboration with project members.

Excluded patients were otherwise offered help by our skilled professionals such as psychologists, as a part of the highly specialized rehabilitation.

The designated project personnel introduced eligible participants to the project, and staff members at the SCI centers were informed of participation in order to fit in the supplementary mentoring with the ongoing standard care and rehabilitation.

\section{Mentors}

A nationwide corps of volunteer peer mentors was established. Some of the mentors were recruited from previously established peer-activities at the centers. Others were volunteers that contacted us at project start after information was provided at the Danish consumer organization's website (www.RYK.dk) and published in social media, such as Facebook ${ }^{\mathrm{TM}}$. Mentors were required to possess a substantial (i.e. minimum of 2 years post $\mathrm{SCI}$ ) experience of living with the consequences of SCI. They should be considered to having a settled view of their own situation and to be open-minded and tolerant. All these qualities were assessed by a conference between staff members and project group professionals, who had knowledge of the mentors' current situation. This was possible, due a national life-long follow-up system with regularly recurring out-patient control visits at the outpatient clinic of the centers.

Before the mentoring sessions commenced, the mentors attended one introductory workshop each. Mentors were introduced to the following themes: ethics, legal conditions, confidentiality, and the role as volunteer peer mentor, i.e. what is expected from me? During the workshop, it was emphasized that peer mentors are not supposed to provide medical advice, whereas they were encouraged to share their personal experiences with the mentees.

The workshops lasted $\sim 3 \mathrm{~h}$ and took place in groups at the two centers. The introductory workshop was repeated twice at each center in order to obtain complete participation. The charge nurses, psychologists, and the designated project personnel from the respective centers led the introduction. A few mentors, who were not able to participate in 
group workshops, were introduced individually and face-toface by project personnel.

At subsequent meetings, organized by project personnel, mentors were invited to exchange their experiences amongst them. However, the requirement of maintaining the confidentiality regarding the mentees was underlined. If needed, professional support was available to all mentors throughout the project period.

All volunteer mentors worked as volunteers but were economically compensated for transportation costs.

\section{Project personnel}

At the two centers a total of four persons were employed part-time after they had applied for participation in the project. At each of the two centers a healthcare professional was employed for $5 \mathrm{~h} /$ week and a person with personal experience from SCI was employed with the tittle of mentor coordinator for $11 \mathrm{~h} /$ week. In conjunction, their job was (a) to introduce the project to eligible patients, (b) to match the mentees with suitable mentors, (c) to coordinate the mentor-mentee meetings, (d) to provide all mentees with questionnaires, and furthermore, and (e) to ensure that all practical tasks related to the project were solved.

\section{Peer mentoring intervention}

The mentor sessions were conducted as one-to-one meetings between mentor and mentee. Meetings could take place at the rehabilitation center (in a private room or in a more common area) or elsewhere if preferred. Meetings could occur anytime throughout the rehabilitation period, and the appropriate timing of initiating the sessions was based on a joint decision, made by the mentee, the interdisciplinary team, and the project members. There was no time limit for the duration of each meeting.

The participating mentees gave written and verbal consent of participation. Each participant was offered up to three formal (i.e. not incidental) sessions with a mentor as a start. In special cases, when it was considered necessary for the sake of the participants, project personnel could give permission to have more sessions. Mentors were individually chosen to match their specific mentees regarding age, gender, level of functioning or disability, vocational or leisure interests, or other more specific parameters as defined by the mentee. Mentees were asked to complete a questionnaire prior to the first mentor session and immediately after the final session took place. The questionnaires were short in order to keep the participants' load at a low level, $\sim 60$ questions before the first session and 50 questions after the last session.

\section{Statistics/data analysis}

Data were analyzed with the software package STATA 15. (Texas, US ${ }^{\mathrm{TM}}$ ). Categorical data were reported as medians with 10th, 25th, 75th, and 90th percentiles (Box-Whisker plots). The sign-rank was used in paired comparisons or when considering more than two groups, the Kruskal-Wallis was applied for categorical data. With groups of less than five, Fischer's exact test was applied.

Data showing normal distribution after usual testing of normality (diagnostic Q plots, qnorm and use of histograms) were reported as means with standard deviations. Student's $t$ test was applied in case of normal distribution, and $t$ test values below 0.05 were considered significant.

SF-36 questions [32]: each item (from 9a-9i) was scored from: (1) All of the time, (2) Most of the time, (3) A good bit of the time, (4) Some of the time, (5) A little of the time, and (6) None of the time. In 9a, 9d, 9e, and $9 \mathrm{~h}$ obtaining lower scores was better, whereas in $9 \mathrm{~b}, 9 \mathrm{c}, 9 \mathrm{f}, 9 \mathrm{~g}$, and $9 \mathrm{i}$ higher scores were preferable.

\section{Results}

\section{Mentors}

A nationwide corps of volunteer peer mentors was established. During a 1 year project period, 57 mentors were introduced to the program. Mentors were 37 men and 20 women, aged between 20 and 76 years. Of these, 34 mentors (22 men and 12 women) were involved in mentor sessions during the time-frame of the project. They were aged between 28 and 71 years. Mean age was of 49.4 years.

No mentors dropped out during the project period. Subsequently two mentors left the corps at their own request, due to personal matters.

Nineteen mentors had meetings with only one mentee, while 11 had meetings with two mentees, three had meetings with three mentees, and one had meetings with as much as five mentees. In three cases, one mentee had two consecutive mentors (one at a time).

\section{Mentees}

Fifty-three patients were included as mentees in the project. (See Table 1 for further details).

All 53 participated in mentor sessions. The data from one participant were subsequently withdrawn from the project due to protocol violation (did not fulfill inclusion criteria), leaving a total number of 52 participants (men: $n=33$ (63\%), women: $n=19(37 \%)$ ) aged between 19 and 77 years at participation. Self-reported data showed that $28.8 \%$ sustained a tetraplegia and $40.4 \%$ paraplegia, while almost a 
Table 1 Study population characteristics

\begin{tabular}{|c|c|}
\hline Characteristics & $\begin{array}{l}\text { Menteés participating } \\
n=52\end{array}$ \\
\hline $\begin{array}{l}\text { Age at participation (median) (25th } \\
75 \text { th percentile) }\end{array}$ & $50(3458)$ \\
\hline $\begin{array}{l}\text { Years since injury (median) (25th } 75 \text { th } \\
\text { percentile) }\end{array}$ & $0.34\left(\begin{array}{lll}0.25 & 0.51)\end{array}\right.$ \\
\hline \multicolumn{2}{|l|}{ Gender $n(\%)$} \\
\hline Men & $33(63.5)$ \\
\hline Women & $19(36.5)$ \\
\hline \multicolumn{2}{|l|}{ Spinal cord level $n(\%)$} \\
\hline Tetraplegia & $15(28.8)$ \\
\hline Paraplegia & $21(40.4)$ \\
\hline Missing & $16(30.8)$ \\
\hline \multicolumn{2}{|l|}{ Cause of injury $n(\%)$} \\
\hline Trauma & $23(44.2)$ \\
\hline Disease & $29(55.8)$ \\
\hline \multicolumn{2}{|l|}{ Participants with pain $n(\%)$} \\
\hline Yes & $39(75.0)$ \\
\hline No & $13(25.0)$ \\
\hline \multicolumn{2}{|l|}{ Social status $n(\%)$} \\
\hline Married or companion & $30(57.7)$ \\
\hline Live alone & $15(28.8)$ \\
\hline Living with parents & $3(5.8)$ \\
\hline Other & $4(7.7)$ \\
\hline \multicolumn{2}{|l|}{ Children } \\
\hline Yes & $35(67.3)$ \\
\hline No & $17(32.7)$ \\
\hline
\end{tabular}

third $(30.8 \%)$ did not answer this question. Traumatic cause was reported by $40.2 \%$ and $55.8 \%$ reported a nontraumatic origin of SCI. Two participants did not complete the followup questionnaire after the last mentor session.

Figure 1 shows a box-and whisker plot of the participants' QoL, rated before and after peer mentoring (International SCI QoL Basic Data Set [4]). At all three NRS-11-point scales, being Life and Personal Circumstances, Physical Health, and Psychological Health in past 4 weeks, participants gained significant improvement (KW, $p=0.01)$.

Reported pain frequency did not significantly change during the mentoring process, with $75-70 \%$ reporting ongoing pain (sign-rank, $p=0.48$ ). The average 11-point NRS rating was a median 4 (25th; 75 th $1 ; 5.5)$ prior to peer mentoring, and a median of $3(25$ th; 75 th $0 ; 6)$ post mentoring (signed-rank, $p=0.86$ ).

SF-36 standard data showed significant improvement of depression-related items in five out of nine items. The remaining four items did not improve significantly, although the noted change in all cases was in a positive direction (see Table 2). In detail, Did you feel full of pep

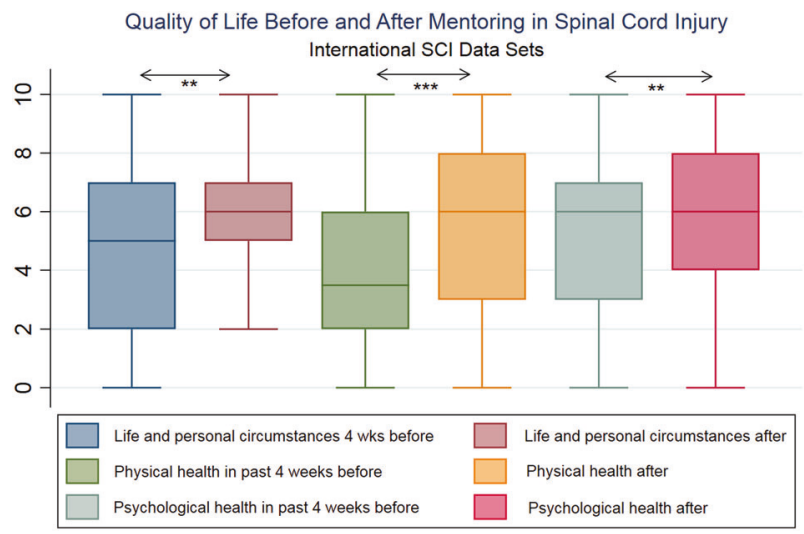

Fig. 1 Quality of life before and after mentoring in spinal cord injury. International SCI data sets

was improved, Did you have a lot of energy was improved, Did you feel worn out was improved, as was Have you been a happy person and Did you feel tired.

\section{Number of meetings with mentors}

The number of meetings between mentee and mentor was registered. Of the 50 completing the final questionnaire, 11 (22\%) reported that they had one meeting, 13 (26\%) had two meetings, 19 (38\%) had three meetings, and 7 (14\%) reported more than three meetings. Thirty-two mentees (64\%) found the number of meetings appropriate, 17 (34\%) would have preferred further meetings. One mentee $(2 \%)$ reported that he had too many meetings, and one did not answer. There was no correlation between the number of meetings and the reported satisfaction with the number of meetings. Details on non-participants as compared with participants are reported in tables 3 (demographics) and 4.

\section{Topics discussed during mentoring sessions}

The most frequently discussed topics were "life after hospitalization" (81\%) and issues regarding practical problems associated with the mentees' new situation (73\%). See Table 4 for more information.

Satisfaction with peer mentoring Of the 50 participants answering the final questionnaire, 46 (94\%) reported that they would recommend to meet with a peer mentor to other SCI in-patients, whereas $3(6 \%)$ did not know, and one did not answer the particular question. No one $(0 \%)$ would advice others not to meet with a peer mentor.

\section{Nonparticipants}

Ninety-six persons (men: $n=58$ (60\%), women: $n=38$ (40\%)) completed the nonparticipant questionnaire. Of these, $59 \%$ were discharged from their initial rehabilitation. 
Table 2 Depression-related items (SF-36) scored by spinal cord injury in-patients before and after participation in a nationwide mentor program
Table 3 Participants and nonparticipants in mentor-mentee project

\begin{tabular}{|c|c|c|c|c|c|}
\hline \multirow[t]{2}{*}{ SF-36 (During the past 4 weeks) } & \multirow[t]{2}{*}{$N$} & \multicolumn{2}{|l|}{ Score } & \multirow{2}{*}{$\begin{array}{l}\text { Difference } \\
Z \text {-value }\end{array}$} & \multirow{2}{*}{$\begin{array}{l}\text { Sign-rank } \\
P\end{array}$} \\
\hline & & Before & After & & \\
\hline a) Did you feel full of pep? & 50 & 3.92 & 3.42 & -3.45 & 0.00 \\
\hline b) Have you been a very nervous person? & 50 & 4.56 & 4.82 & -1.26 & 0.21 \\
\hline $\begin{array}{l}\text { c) Have you felt so down in the dumps that nothing } \\
\text { could cheer you up? }\end{array}$ & 50 & 4.94 & 5.08 & -1.22 & 0.22 \\
\hline d) Have you felt calm and peaceful? & 50 & 3.52 & 3.20 & -1.74 & 0.08 \\
\hline e) Did you have a lot of energy? & 50 & 4.34 & 3.82 & -2.74 & 0.01 \\
\hline f) Have you felt downhearted and blue? & 50 & 4.12 & 4.42 & -1.94 & 0.05 \\
\hline g) Did you feel worn out? & 50 & 3.98 & 4.44 & -2.16 & 0.03 \\
\hline h) Have you been a happy person? & 50 & 3.68 & 3.26 & -2.27 & 0.02 \\
\hline i) Did you feel tired? & 50 & 3.30 & 3.78 & -2.66 & 0.01 \\
\hline
\end{tabular}

SF-36: Standard Form 36 questionnaire subscale applied

Scores ranged from: 1 All of the time, 2 Most of the time, 3 A good bit of the time, 4 Some of the time, 5 A little of the time, 6 None of the time

Italic rows are more positive with LOWER scores, non italic rows are more positive with HIGHER scores $* P<0.05$

\begin{tabular}{lllllll}
\hline & $\begin{array}{l}\text { Participants } \\
(N=52)\end{array}$ & $\begin{array}{l}\text { Non-Participants } \\
(N=96)\end{array}$ & $P$-value \\
\hline Gender (Percentage women (CI95)) & 19 & $37(24 ; 51)$ & 38 & $40(30 ; 50)$ & NS & $\#)$ \\
Age (Median 25th 75th percentile) & 50 & $(34 ; 58)$ & 62 & $(49 ; 70)$ & $p<0.001$ & $\# \#)$ \\
First time admission (cases, percentage (CI95)) & 49 & $96(87 ; 100)$ & 57 & $59(49 ; 69)$ & $p<0.001$ & $\#)$ \\
SCI Traumatic cases, percentage (CI95) & 23 & $44(30 ; 59)$ & 36 & $38(28 ; 48)$ & NS & $\#)$ \\
\hline
\end{tabular}

\# Fischer's Exact/Chi2, \#\# Kruskal-Wallis

Table 4 In-hospital peer-mentor contact

\begin{tabular}{|c|c|c|c|c|c|c|c|}
\hline & \multicolumn{3}{|c|}{ Participants $(N=52)$} & \multicolumn{4}{|c|}{ Non-participants $(N=96)$} \\
\hline & Yes & Percentage & $(\mathrm{Ci95})$ & Yes & Percentage & $(\mathrm{Ci} 95)$ & Fischer's exact \\
\hline I have met the mentor contact & 46 & 88 & $(77 ; 96)$ & 60 & 63 & $(52 ; 72)$ & $p<0.001$ \\
\hline I have talked with the mentor contact & 35 & 67 & $(53 ; 80)$ & 40 & 42 & $(32 ; 52)$ & NS \\
\hline I have participated in mentor contact activities & 12 & 23 & $(13 ; 37)$ & 11 & 11 & $(6 ; 20)$ & NS \\
\hline \multicolumn{8}{|l|}{ Subjects to discuss with mentor contact during stay } \\
\hline We talked about disease/accident that caused my SCI & 31 & 60 & $(45 ; 73)$ & 16 & 17 & $(10 ; 26)$ & $p<0.001$ \\
\hline We talked about my life during in-hospital rehabilitation & 23 & 44 & $(30 ; 59)$ & 12 & 13 & $(7 ; 21)$ & $p<0.001$ \\
\hline We talked about my life afterwards the hospital & 42 & 81 & $(67 ; 90)$ & 18 & 19 & $(12 ; 28)$ & $p<0.001$ \\
\hline We talked about my family & 24 & 46 & $(32 ; 61)$ & 10 & 10 & $(5 ; 18)$ & $p<0.001$ \\
\hline We talked about my friends & 16 & 31 & $(19 ; 45)$ & 5 & 5 & $(2 ; 11)$ & $p<0.001$ \\
\hline We talked about my work/education & 24 & 46 & $(32 ; 61)$ & 12 & 13 & $(7 ; 21)$ & $p<0.001$ \\
\hline We talked about how to provide for oneself & 8 & 15 & $(7 ; 28)$ & 7 & 7 & $(3 ; 14)$ & NS \\
\hline We talked about leasure activities, hobbies & 24 & 46 & $(32 ; 61)$ & 16 & 17 & $(10 ; 26)$ & $p<0.001$ \\
\hline We talked about intimacy, sexuality & 14 & 27 & $(16 ; 41)$ & 2 & 2 & $(0 ; 7)$ & $p<0.001$ \\
\hline We talked about bladder and bowel issues & 21 & 40 & $(27 ; 55)$ & 8 & 8 & $(4 ; 16)$ & $p<0.001$ \\
\hline We talked about pain & 20 & 38 & $(25 ; 53)$ & 10 & 10 & $(5 ; 18)$ & $p<0.001$ \\
\hline We talked about accessibility aids & 32 & 62 & $(47 ; 75)$ & 14 & 15 & $(8 ; 23)$ & $p<0.001$ \\
\hline We talked about practical problems & 38 & 73 & $(59 ; 84)$ & 12 & 13 & $(7 ; 21)$ & $p<0.001$ \\
\hline Other issues & 11 & 21 & $(11 ; 35)$ & 10 & 10 & $(5 ; 18)$ & NS \\
\hline Importance of mentor contact during stay & & & & 27 & 28 & $(19 ; 38)$ & \\
\hline
\end{tabular}


Table 4 shows difference in the topics approached by mentees with their mentors and nonparticipating SCI inpatients with the mentor contact, where much more subjects are discussed in the mentor-mentee relationship. Sixty-three percent of nonpartipants had met the mentor contact and $42 \%$ talked to him/her. Eleven percent had participated in mentor contact activities, and $28 \%$ of nonparticipants found it was important that mentor contacts were present at the hospital.

\section{Discussion}

The main purpose of this study was to investigate whether it was feasible to organize a nationwide mentor corps and provide mentoring in highly specialized SCI rehabilitation hospitals. To our knowledge, this is the first nationwide study regarding peer mentoring among persons suffering from SCI. As there are only two SCI rehabilitation centers in Denmark and only a limited number of persons living with the consequences of SCI, it was possible to conduct and complete the project with a high degree of control and stringency. The establishment of a nationwide mentoring corps ensured that both SCI centers, despite the limited extent of mentoring, could benefit from the overall experience with resulting increase in the quality of work.

One task within the present study was recruiting persons that were suitable and qualified for being included in a corps of mentors. Not all individuals with SCI can be mentors [10]. Mentors do not necessarily need professional qualifications in order to share personal experiences and knowledge with newly injured persons, but some specific personal qualities are needed. Mentors should be empathetic and be able to listen, should be communicative and direct, should be sincere, ethical and trustworthy. Furthermore, they should have a broad range of positive characteristics, be comfortable with themselves, and open to others [10]. The above mentioned qualities could qualify you to be able to have a rewarding partnership with a newly injured and more inexperienced person, but several organizations recommend training to cope with the task [10] in order to improve the outcome. Since the study did not obtain data regarding the mentors' qualifications in our project, it is not possible to draw conclusions regarding e.g. correlations between mentors' qualifications and mentees' satisfaction with mentoring sessions.

When volunteer peers are involved in the rehabilitation process it is of importance to shield and protect them in their work. They should be prepared at best for the stressful situations that may arise during the sessions, and ongoing support should be available as requested. In this study all mentors were invited to an introductory workshop, in which they were given a brief introduction to selected topics, and they were invited to share their experiences within the whole mentor group at the centers. Furthermore, mentors were encouraged to seek help and support at the centers when needed. However, future studies should formally establish an ongoing support of mentors, as recommended by Chase [10].

In connection with the mentoring sessions was obtained self-reported data from the mentees. Pain was frequently encountered and of moderate intensity, however, no change in pain during the project period was found. Participating mentees reported significant improvement in both physical and psychological QoL dimensions. These findings correspond to those of Finnerup et al. [5] who reported slight but significant improvement of QoL during the first year after injury. Their study did not specify which efforts, in particular, made a contribution to improving QoL, so we do not know if peer mentoring was important for these observed improvements. However, QoL at least did obviously not deteriorate in the mentee as a result of peer mentoring. In addition, the SF-36 revealed a significant change for the better in six out of nine depression-related questions for study participants in the present study.

The number of meetings between mentees and mentors varied from one to three or more. More than half of the mentees were satisfied with the number, while a third answered that they would have liked more. There was no dose-response association, e.g. no correlation between the number of meetings, and the reported satisfaction with the number of meetings. One meeting could be beneficial, however, future studies should investigate the optimal number and extent of meetings. Intensive peer mentoring during and after rehabilitation have shown positive dose relationship with resulting increase of self-efficacy amongst mentees [18].

During the meetings between mentees and mentors, several topics were discussed. Most of the mentees $(81 \%)$ reported that they had discussed their "life after hospitalization". This is a very large and comprehensive topic that is not particularly specific, and presumably most mentees could recognize this topic in their mentoring sessions. Practical problems associated with the mentees' new life situation is more specific, and $73 \%$ discussed this issue. In order to prepare future peers and professionals for their work and to improve the quality of rehabilitation it would be helpful to more precisely investigating, which topics and issues the mentees need to discuss at a given time. This could be done in focus group interviews before and after peer mentoring participation.

After the mentoring sessions $94 \%$ reported that they would recommend others to meet with a peer mentor, and no one would recommend against it. The establishment is therefore considered widely accepted by participating SCI in-patients. Of three uncertain mentees regarding their recommendation, 
we have no further knowledge on this uncertainty. Recommendation should be further explored in future studies.

Data from the 96 nonparticipants did not differ from participants in distribution of age, gender. The nonparticipants reported which topics were discussed with the mentor coordinators. Some of the more intimate subjects like bladder and sexuality were not discussed here. Hobbies and leasure activities were discussed by some.

It would have been relevant to know the number of nonparticipants who were eligible to the project and contacted for participation, but had declined. We experienced that a few eligible patients did not want to participate in the project because participation entailed an expectation of completing two questionnaires. This was not documented, and in general the study failed to ask nonparticipants, if they would have met with a mentor if possible; however, only $28 \%$ of nonparticipants mentioned the present in-hospital mentor contact as of importance during their stay.

During the project period, project personnel with SCI were employed as mentor coordinators, and they were present at the centers for $11 \mathrm{~h} /$ week. After the project completion, both rehabilitation centers decided to prolong the employments for the two persons for a longer and not yet completed period. They have become essential assets as contact persons for patients and mentors and as the patients' representatives in the daily work at the centers. It is however arguable whether mentor coordinators become intramural "professionals" when time goes by. This issue needs further investigation.

\section{Conclusion}

Organizing a nationwide volunteer mentor corps is feasible and peer mentoring during primary rehabilitation in highly specialized centers is feasible, accepted by rehabilitation staff and widely recommended by participating in-patients.

\section{Future directions and implications}

The results of this study suggest that volunteer peer mentorship in primary rehabilitation of persons with SCI is a feasible and rewarding effort. The establishment of appropriate education programs in order to prepare SCI mentors for the task is needed. In a small country like Denmark, this should continue as a nationwide joint task.

The promising results of this feasibility study call for follow up randomized controlled studies. Focus interview studies could further substantiate findings from the present study. Peer mentoring studies using controlled designs could improve measuring of specific effects, e.g. self-efficacy, resilience and other extents of peer mentoring.

\section{Data archiving}

The datasets generated and analyzed during the current study are available from the corresponding author on reasonable request.

Acknowledgements We would like to thank all participants, the staff and management at the two rehabilitation centers, and the Danish consumer organization RYK for their support.

Funding The study received unrestricted grants donated by TRYG Fonden, Bevica Fonden, Vanfoerefonden, Aage \& Johanne LouisHansens Fond, Spejdernes Genbrug.

Authors' contributions DDH, FBS, and HK conceptualized and designed the study. JLS, HK, and DDH prepared and coordinated data analyses and interpretations. JLS and HK analyzed the data. All authors contributed to the overall interpretation and contextualization. DDH and HK wrote the first draft of the manuscript. All authors participated in the critical review and afterwards approved the manuscript.

\section{Compliance with ethical standards}

Conflict of interest The authors declare that they have no conflict of interest.

Ethical statement The study was conducted in concordance with the Helsinki II declaration. The study was approved by the Danish Regional Ethics Committee, (journal number 2007-58-0010). We certify that all applicable institutional and governmental regulations concerning the ethical use of human volunteers were followed during the course of this research. Mentors were adequately instructed to fulfill their role, and were closely followed and were offered help and supervision if requested.

Publisher's note: Springer Nature remains neutral with regard to jurisdictional claims in published maps and institutional affiliations.

Open Access This article is licensed under a Creative Commons Attribution 4.0 International License, which permits use, sharing, adaptation, distribution and reproduction in any medium or format, as long as you give appropriate credit to the original author(s) and the source, provide a link to the Creative Commons license, and indicate if changes were made. The images or other third party material in this article are included in the article's Creative Commons license, unless indicated otherwise in a credit line to the material. If material is not included in the article's Creative Commons license and your intended use is not permitted by statutory regulation or exceeds the permitted use, you will need to obtain permission directly from the copyright holder. To view a copy of this license, visit http://creativecommons. org/licenses/by/4.0/.

\section{References}

1. World Health Organization, International Spinal Cord Society. International perspectives on spinal cord injury. World Health Organization; 2013.

2. Post MW, van Leeuwen CM. Psychosocial issues in spinal cord injury: a review. Spinal Cord. 2012;50:382-9. 
3. Boakye M, Leigh BC, Skelly AC. Quality of life in persons with spinal cord injury: comparisons with other populations. J Neurosurg Spine. 2012;17(1 Suppl):29-37.

4. Lidal IB, Veenstra M, Hjeltnes N, Biering-Sorensen F. Healthrelated quality of life in persons with long-standing spinal cord injury. Spinal Cord. 2008;46:710-5.

5. Finnerup NB, Jensen MP, Norrbrink C, Trok K, Johannesen IL, Jensen TS, et al. A prospective study of pain and psychological functioning following traumatic spinal cord injury. Spinal Cord. 2016;54:816-21.

6. Beauchamp MR, Scarlett LJ, Ruissen GR, Connelly CE, McBride $\mathrm{CB}$, Casemore $\mathrm{S}$, et al. Peer mentoring of adults with spinal cord injury: a transformational leadership perspective. Disabil Rehabil. 2016;38:1884-92.

7. Sweet SN, Noreau L, Leblond J, Martin Ginis KA. Peer support need fulfillment among adults with spinal cord injury: relationships with participation, life satisfaction and individual characteristics. Disabil Rehabil. 2016;38:558-65.

8. Gimigliano F, Negrini S. The World Health Organization "Rehabilitation 2030: a call for action". Eur J Phys Rehabil Med. 2017;53:155-68.

9. Dennis CL. Peer support within a health care context: a concept analysis. Int J Nurs Stud. 2003;40:321-32.

10. Chase T. Peer Counseling: A Holistic Psychosocial Rehabilitation Approach. In: Chhabra HS, editor. ISCoS text book on comprehensive management of spinal cord injuries. 1st ed. New Delhi: Wolters Klüver (India) Pvt. Ltd; 2015.

11. Dale J, Williams S, Bowyer V. What is the effect of peer support on diabetes outcomes in adults? A systematic review. Diabet Med. 2012;29:1361-77.

12. Tang TS, Ayala GX, Cherrington A, Rana G. A review of volunteer-based peer support interventions in diabetes. Diabetes Spectr. 2011;24:85-98.

13. Hoey LM, Ieropoli SC, White VM, Jefford M. Systematic review of peer-support programs for people with cancer. Patient Educ Couns. 2008;70:315-37.

14. Lloyd-Evans B, Mayo-Wilson E, Harrison B, Istead H, Brown E, Pilling $\mathrm{S}$, et al. A systematic review and meta-analysis of randomised controlled trials of peer support for people with severe mental illness. BMC Psychiatry. 2014;14:39.

15. Mahlke CI, Krämer UM, Becker T, Bock T. Peer support in mental health services. Curr Opin Psychiatry. 2014;27:276-81.

16. Morris RP, Fletcher-Smith JC, Radford KA. A systematic review of peer mentoring interventions for people with traumatic brain injury. Clin Rehabil. 2017;31:1030-8.

17. Haas BM, Price L, Freeman JA. Qualitative evaluation of a community peer support service for people with spinal cord injury. Spinal Cord. 2013;51:295-9.
18. Gassaway J, Jones ML, Sweatman WM, Hong M, Anziano P, DeVault K. Effects of peer mentoring on self-efficacy and hospital readmission after inpatient rehabilitation of individuals with spinal cord injury: a randomized controlled trial. Arch Phys Med Rehabil. 2017;98:1526-1534.e2.

19. Barclay L, McDonald R, Lentin P, Bourke-Taylor H. Facilitators and barriers to social and community participation following spinal cord injury. Aust Occup Ther J. 2016;63:19-28.

20. Divanoglou A, Georgiou M. Perceived effectiveness and mechanisms of community peer-based programmes for spinal cord injuries-a systematic review of qualitative findings. Spinal Cord. 2017;55:225-34.

21. Stokes M. Physical management in neurological rehabilitation. Elsevier Health Sciences; 2004. ISBN 978-0-7234-3285-2.

22. Unger J, Singh H, Mansfield A, Hitzig SL, Lenton E, Musselman KE. The experiences of physical rehabilitation in individuals with spinal cord injuries: a qualitative thematic synthesis. Disabil Rehabil. 2019;41:1367-83.

23. Biering-Sørensen F. Rygmarvsskade - den moderne behandling. Ugeskr Læg. 2001;163:2766-9.

24. Lundberg AS, Andersen MK, Kasch H, Hansen RM. Patienter med rygmarvsskade har mange følgetilstande. Ugeskr Laege. 2015;177:V06150476.

25. Noe BB, Bjerrum M, Angel S. Expectations, worries and wishes: the challenges of returning to home after initial hospital rehabilitation for traumatic spinal cord injury. Int J Phys Med Rehabil. 2014;2:225.

26. Lucke KT, Coccia H, Goode JS, Lucke JF. Quality of life in spinal cord injured individuals and their caregivers during the initial 6 months following rehabilitation. Qual Life Res. 2004;13:97-110.

27. Charlifue S, Post MW, Biering-Sorensen F, Catz A, Dijkers M, Geyh S, et al. International spinal cord injury quality of life basic data set. Spinal Cord. 2012;50:672-5.

28. Ware JE Jr, Sherbourne CD. The MOS 36-item short-form health survey (SF-36). I. conceptual framework and item selection. Med Care. 1992;30:473-83.

29. Dworkin RH, Turk DC, Farrar JT, Haythornthwaite JA, Jensen MP, Katz NP, et al. Core outcome measures for chronic pain clinical trials: IMMPACT recommendations. Pain. 2005;113:9-19.

30. Forchheimer M, McAweeney M, Tate DG. Use of the SF-36 among persons with spinal cord injury. Am J Phys Med Rehabil. 2004;83:390-5.

31. Wilson JR, Hashimoto RE, Dettori JR, Fehlings MG. Spinal cord injury and quality of life: a systematic review of outcome measures. Evid Based Spine Care J. 2011;2:37-44.

32. Ware JE, Kosinski M. SF-36 physical \& mental health summary scales: a manual for users of version 1.: Quality Metric; 2001. 